\title{
Pea protein hydrolysate as a factor modulating the adhesion of bacteria to enterocytes, epithelial proliferation and cytokine secretion - an in vitro study
}

\author{
DOMINIKA ŚWIĄTECKA, LIDIA HANNA MARKIEWICZ, BARBARA WRÓBLEWSKA
}

Department of Immunology and Food Microbiology, Institute of Animal Reproduction and Food Research, Polish Academy of Sciences, Olsztyn, Poland

\begin{abstract}
Food proteins may release biologically active peptides in a consequence of enzymatic degradation. Such hydrolysates may affect the balance of intestinal bacteria and their adhesive potential. This study aimed at determining the impact of the pea protein extract and its pepsin hydrolysate on the adhesion of heterogeneous bacterial culture to Caco-2 cell line, and their impact on enterocytes as a function of proliferative and immunosecretive activity. The total number of immobilized bacteria was established with fluorescent marker DAPI, whereas their biodiversity was assessed with a FISH technique. Enterocytic proliferation was assessed with the BrdU test and a cytokine secretion was analyzed with the ELISA assay. Obtained results demonstrated that the pea protein hydrolysate stimulated adhesion of Lactobacillus/Enterococcus and did not influence the adhesion of Escherichia coli. The pea protein extract and its hydrolysate hindered mitotic division of Caco-2 cells as well as triggered a significant higher secretion of IL-8. Pea protein hydrolysate may therefore be considered as a potential modulator of bacterial adhesion and metabolic activity of enterocytes. Hence, it may impact the balance of gut microbiota as well as the maintenance and strengthening of the intestinal barrier. In consequence, it may modulate a human health status.
\end{abstract}

Key words: pepsin hydrolysis, Caco-2 cell line, bacterial adhesion, cytokine secretion, proliferation of enterocytes.

(Centr Eur J Immunol 2012; 37 (3): 227-231)

\section{Introduction}

Food proteins are believed to encrypt peptides that, when released by gastrointestinal enzymes, display a broad spectrum of biological activity thus influencing the health status of a consumer [1, 2]. Peptides and glycopeptides released by the hydrolysis of proteins may significantly modulate the condition and activity of intestinal ecosystem, particularly bacteria and intestinal cells. Thus, such hydrolysates may exert an effect far beyond nutrient supply, acting directly in the intestinal tract or via receptors located on the surfaces of the cells or via pathways of intracellular signal transduction [2]. Additionally, hydrolysis enhances food digestibility, what is of great importance in terms of legumes, which digestibility is hindered [3]. Pea proteins are of nutritional importance due to abundance of proteins, carbohydrates, fibre, vitamins and minerals, however they also contain low amount of antinutritional factors [4]. Recent studies demonstrated that pea protein hydrolysate diversely modulated physiological activity of planktonic and immobilized bacteria typical for small intestinal region [5]. The observed detrimental effect on planktonic bacteria was abolished in the case of bacteria immobilized to the solid surfaces, whereas lactobacilli displayed adaptive properties enabling them to utilize pea proteins hydrolysates regardless their state of existence [5]. The diet enriched with the pea protein hydrolysate was suggested to potentially beneficially modulate small intestinal bacterial flora via the stimulation of the proliferation rate, metabolic activity and adhesion of lactic acid bacteria [5].

Correspondence: Dominika Świątecka, Department of Immunology and Food Microbiology at the Institute of Animal Reproduction and Food Research of the Polish Academy of Sciences, J. Tuwima 10, 10-748 Olsztyn, Poland; tel. +48 8952346 57, fax +48 895240124 , e-mail: d.swiatecka@pan.olsztyn.pl 
Therefore, this study aimed at establishing the influence of the pea protein hydrolysate on the physiological activity of bacteria commonly colonizing the human small intestine. However, the biological activity of the mentioned hydrolysate required further in vitro studies. For that reason, this study aimed at estimation of the impact of the pea protein extract and the pea protein hydrolysate on the adhesion of heterogeneous bacterial population to the surface of Caco2 cells as well as on their proliferation and IL-8 secretion.

\section{Material and methods}

\section{Protein extraction from raw peas}

Raw peas (Ramrod type) were delivered from the Production and Experimental Research Station, located in Batcyny, Poland and were subsequently ground to flour in the laboratory mill.

Proteins were extracted from ground pea flour according to Simpson [6]. In short, $35 \mathrm{~g}$ of the flour were extracted with $140 \mathrm{ml}$ of $50 \mathrm{mM}$ Tris- $\mathrm{HCl}(\mathrm{pH} \mathrm{8.8)}$ for 1 hour at $4^{\circ} \mathrm{C}$ and subsequently centrifuged (20000 g, $\left.20 \mathrm{~min}\right)$. The supernatant was then dialysed at $4^{\circ} \mathrm{C}$ for 48 hours against distilled water and lyophilised [6-7]. The concentration of proteins was determined with the Bradford's method [8] with bovine serum albumin (BSA) as a standard.

\section{Pepsin hydrolysis of pea proteins}

The kinetic of pea protein hydrolysis was carried out at $\mathrm{pH}$ 2.0. The solution was prepared as follows: $0.6 \mathrm{~g}$ of the pea proteins extract was dissolved in $200 \mathrm{ml}$ of distilled water at $\mathrm{pH} 2.0$ (obtained by addition of $1 \mathrm{M} \mathrm{HCl}$ ) and followed by addition of $10.5 \mathrm{mg}$ of pepsin (90 mAU activity, Sigma, P-7000). The hydrolysis was carried out at $37^{\circ} \mathrm{C}$ for 2 hours and stopped by freezing at $-20^{\circ} \mathrm{C}$.

Obtained protein hydrolysates were filtrated through syringe cellulose filters of pores size $0.22 \mu \mathrm{m}$ (Millipore) and then characterised in terms of the degree of hydrolysis (DH) [5] calculated from the equation of Adler-Nissen [9]. The hydrolysed and non-hydrolysed protein extract were compared by SDS-PAGE according to Laemmli [10].

\section{Bacterial strains and inoculum preparation}

The strain Enterococcus faecalis PCM 1861 was obtained from the Polish Collection of Microorganisms, Institute of Immunology and Experimental Therapy, Polish Academy of Sciences (Wrocław, Poland), whereas Escherichia coli and Lactobacillus acidophilus were obtained from the Faculty of Food Science, University of Warmia and Mazury (Olsztyn, Poland).

Single bacterial strains were transferred from agar slants into liquid medium (nutrient broth for E. coli, Brain Heart Infusion (BHI) for enterococci and MRS for lactobacilli) and incubated for $24 / 48$ hours at $37^{\circ} \mathrm{C}$. The cultures were refreshed by transferring $0.5 \mathrm{ml}$ into freshly prepared liquid media and again incubated under identical conditions with constant absorbance measurement until reaching $\mathrm{A}_{\gamma=550 \mathrm{~nm}}=0.2$. Such prepared bacterial suspensions were used for inoculation in further microbial analysis.

\section{The Caco-2 cell line}

The Caco-2 cell line was routinely cultured in the filtrated DMEM medium (Dulbecco's Modified Eagle's Medium, Sigma) containing $20 \%$ of inactivated foetal bovine serum (FBS, Gibco), $1 \%$ of non-essential amino acid mixture (NEAA, Gibco) and $1 \%$ of penicillin/streptomycin solution (Sigma). The incubation was carried out at $37^{\circ} \mathrm{C}$ in $5 \%$ of $\mathrm{CO}_{2}$ atmosphere and the humidity of approximately $95 \%$. The 21-day-old Caco-2 cultures were used in the experiments as differentiated and fully confluent cells according to Peterson and Mooseker [11].

\section{The adhesion assay to Caco-2 cells in the presence of pea proteins}

The Caco- 2 cells were seeded at the concentration of $2.5 \times 10^{4}$ cells/well in 96-well standard tissue culture plates (Becton Dickinson). Twenty four hours before the test, the DMEM medium supplemented with penicillin/streptomycin solution was replaced with the same medium without antibiotics. The Caco-2 monolayer was incubated for oneand-a-half-hour at $37^{\circ} \mathrm{C}$ with $50 \mu \mathrm{l}$ of solutions of the pea protein extract $(\mathrm{E})$ and the pea protein hydrolysate $(\mathrm{H})$ at the final concentration of $1 \mathrm{mg} / \mathrm{ml}$. After the incubation the cultures were supplemented with $100 \mu \mathrm{l}$ of an inoculating solution at $\mathrm{pH} 7.0$ containing $40 \%$ L. acidophilus, $30 \%$ E. coli and $30 \%$ E. faecalis suspended in DMEM without antibiotics. The cultures were subjected to further 1.5-hour incubation. The cultures without any pea proteins/ hydrolysate supplementation were treated as controls (C). After the incubation, the media were removed and the cultures were washed out twice with PBS to remove nonadherent bacteria. In order to liberate adhered bacteria from the Caco-2 surface, the cultures were incubated on ice for 10 minutes with $200 \mu \mathrm{l}$ of $0.1 \%$ cold Triton X-100 solution (Sigma). The solutions containing the bacteria were hybridised with EC 1531 and LAB 158 probes and counter-stained with DAPI according to the procedure described by Świątecka et al. [12]. The analyses were conducted in three parallel repetitions.

\section{Proliferation of Caco-2 cells estimated by the BrdU incorporation}

Caco-2 cells were plated in 96-well plates and cultured as described above. To measure DNA synthesis, cells were incubated in the presence of examined substrates at concentration of $1 \mathrm{mg} / \mathrm{ml}$ during 1.5 and 6 hours. After labeling, BrdU incorporation into cellular DNA was measured by a colorimetric immunoassay using a commercially available cell proliferation ELISA kit (Roche, France). Absorbance from peroxidase reaction with OPD (o-Phenylenediamine dihydrochloride) substrate was measured by a scanning multiwell 
spectrophotometer at $492 \mathrm{~nm}$. Each experimental condition was conducted in triplicate. BrdU incorporation for all experiments was expressed as the percentage in comparison to the control which was calculated as $100 \%$.

\section{Determination of interleukin 8 secretion by enzyme linked immunosorbent assay (ELISA)}

Post-confluent cell monolayers were washed two times with pre-wormed PBS. To measure the IL-8 secretion were incubated in the presence of analyzed substrates in concentration: $0.05,0.5$ and $1 \mathrm{mg} / \mathrm{ml}$ during 24 hours. Cytokine production $(\mathrm{pg} / \mathrm{ml})$ were compared with the results obtained for cells incubated in the control medium. Each experimental condition was conducted in triplicate. The content of IL-8 in media was measured using a commercially available ELISA according to the manufacturer's instructions (BD Biosciences, OptEIA, Pharmingen, San Diego, CA).

\section{Statistical analysis}

The Statistica 9 Software was used to conduct statistical analysis of the results obtained. The standard error was used to demonstrate the obtained results. The statistical significance was determined by the variance analysis using the F distribution by Fisher. Differences at the level of $p<0.05$ were consider as significant.

\section{Results}

\section{Hydrolysis of pea protein extract}

The effect of enzymatic degradation of the pea protein extract is presented in Fig 1. Enzymatic activity of pepsin triggered their 7,11 and 15\% hydrolysis at 15, 60 and $20 \mathrm{~min}$, respectively (Fig. 1A).

The SDS-PAGE separation of the pea protein extract (E) and the pea protein hydrolysate (H) (Fig. 1B) showed that pepsin hydrolysis resulted in degradation of high weight fractions, and in a consequence a wide range of peptides of molecular weight below $14.2 \mathrm{kDa}$ appeared. However, two high protein fractions (68.03 kDa and $56.70 \mathrm{kDa})$ demonstrated susceptibility to pepsin hydrolysis.

\section{Influence of pea protein extract and its hydrolysate on bacterial adhesion}

The pea protein extract as well as the pea protein hydrolysate stimulated the adhesion of bacteria to the surface of Caco-2 cells when compared to the control culture (Fig. 2). However, solely the hydrolysate triggered significantly higher number of adherent cells than observed in the control (two times higher) and in the examined extract (oneand-a-half higher). The number of adhered bacteria from the genera of Lactobacillus and Enterococcus was higher than $E$. coli in the control culture and the observed tendency remained in the cultures supplemented with the pea protein extract. However, the positive effect of the hydrolysate on bacterial adhesion resulted from a significantly higher adherence of bacteria from genera Lactobacillus/Enterococcus (Fig. 2).

\section{Impact of pea protein extract and its hydrolysate on proliferation of Caco-2 cells}

The proliferation of the Caco- 2 cells was drastically reduced by both of the analyzed substrates to the level below $20 \%$ of the proliferation observed in the control culture (Fig. 3). The strongest inhibitory impact was exerted by the pea protein hydrolysate (Fig. 3). The hindrance of enterocytic proliferation was deepened in the passage of time, whereas the pea protein hydrolysates maintained the Caco-2 proliferation at constant, low level below $10 \%$ in comparison to the control culture.

\section{Impact of pea proteins extract and hydrolysate on interleukin 8 secretion}

Both of analysed substrates stimulated the secretion of the proinflammatory cytokine IL-8 from the Caco- 2 cells in comparison to the control culture (Fig. 4). This effect was exerted when the pea proteins extract and hydrolysates were present in the cultures at concentration of $0.5 \mathrm{mg} / \mathrm{ml}$. The strongest stimulation of interleukin secretion was observed for the pea protein extract and reached the level of $240 \mathrm{pg} / \mathrm{ml}$.
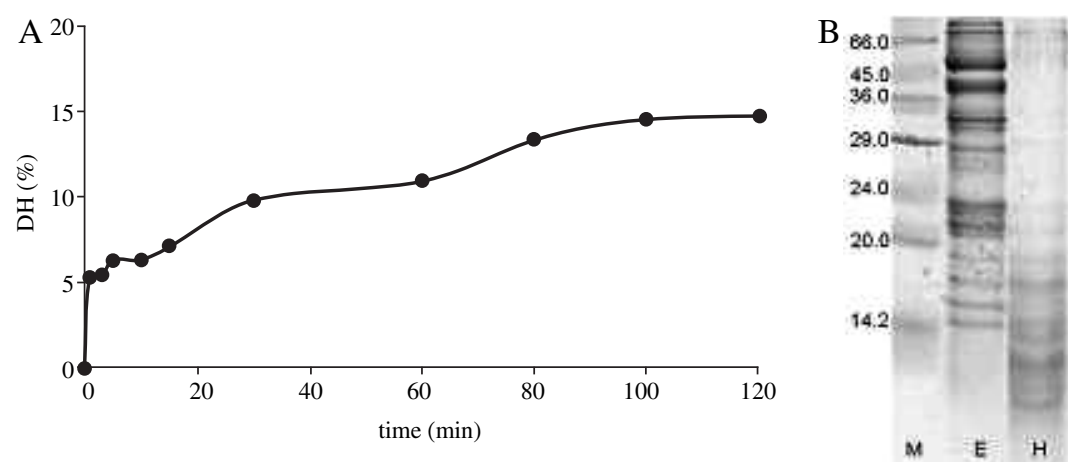

Fig. 1. A - the degree of hydrolysis (DH) of the pea protein extract; B - SDS-PAGE of the pea protein extract (E) and the pea protein hydrolysate $(\mathrm{H}) ; \mathrm{M}-$ molecular weight marker $(\mathrm{kDa})$ 


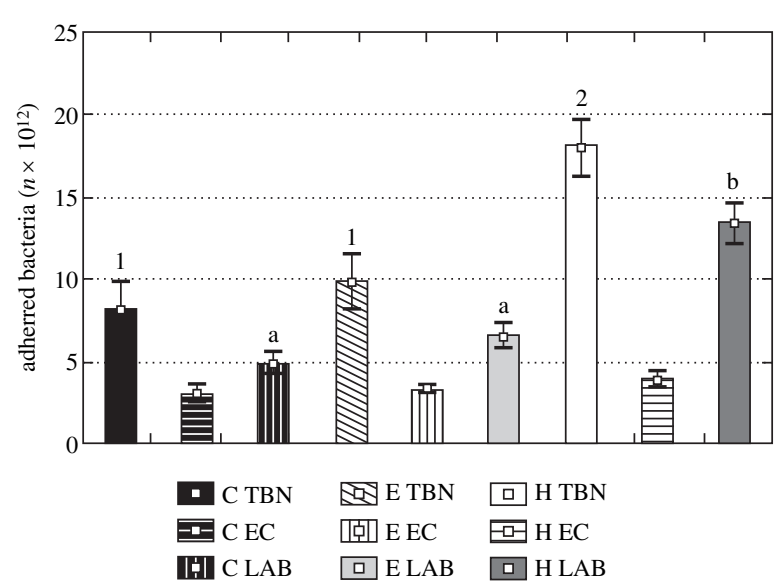

Fig. 2. The impact of the pea protein extract (E) and the pea proteins hydrolysate $(\mathrm{H})$ on bacterial adhesion to the surface of Caco-2 cells. Legend: TBN - total bacterial number; EC adhesion of bacteria from the genus Escherichia, LAB - adhesion of bacteria from genera Lactobacillus and Enterococcus. Significantly different values $(p<0.05)$ of TNB and LAB adhering to Caco-2 cells are indicated with different digits or letters, respectively

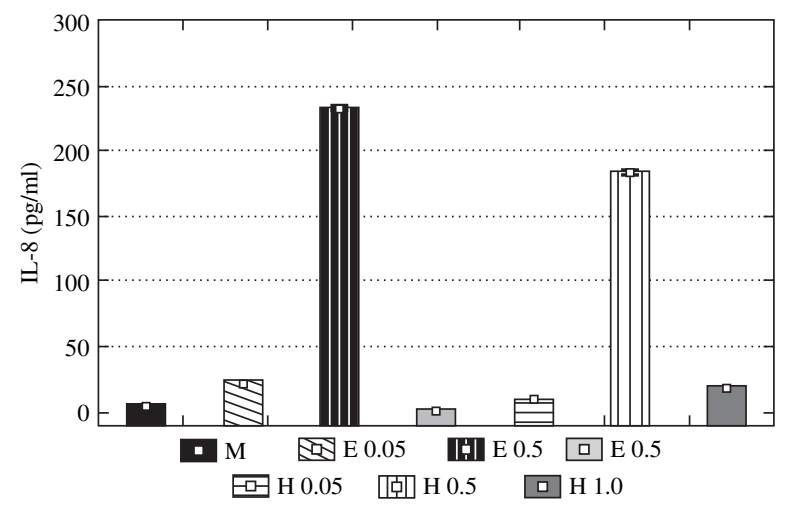

Fig. 4. The impact of the pea protein extract (E) and the pea proteins hydrolysate $(\mathrm{H})$ on secretion of IL-8 from Caco- 2 cells. Legend: $\mathrm{M}$ - control culture; $\mathrm{E}$ - culture supplemented with the pea protein extract in different concentrations $(0.05,0.5$ and $1.0 \mathrm{mg} / \mathrm{ml}), \mathrm{H}$ - culture supplemented with the pea protein hydrolysate in different concentrations $(0.05,0.5$ and 1.0 $\mathrm{mg} / \mathrm{ml}$ ). The secretion of IL- 8 differed significantly among all Caco-2 cultures when supplemented with analyzed substrates

\section{Discussion}

An enzymatic hydrolysis of food proteins is a substantial process frequently used to improve the physical, chemical, functional and nutritional properties of native proteins [13]. It is also used in order to produce a functional food designed to fulfill demands of specific groups of consumers such as children, elderly, sportsmen or for constructing a medical diets $[14,15]$. The $15 \%$ degradation of the pea

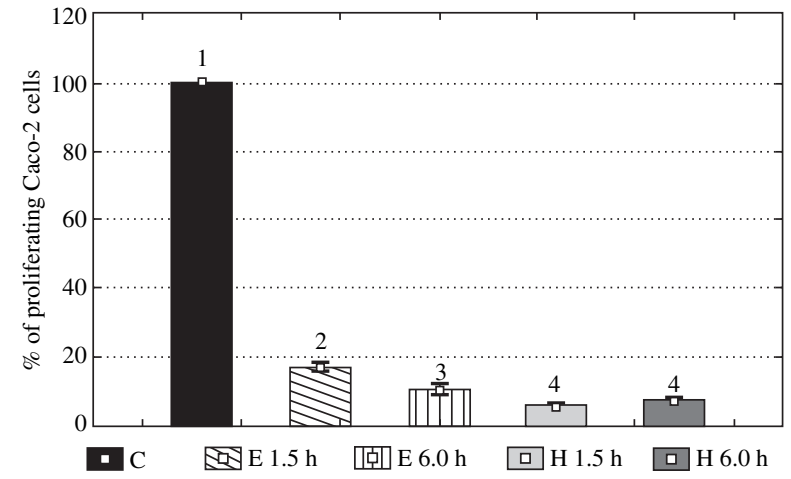

Fig. 3. The impact of the pea protein extract (E) and the pea protein hydrolysate $(\mathrm{H})$ on proliferation of Caco-2 cells. Legend: $\mathrm{C}$ - control culture; $\mathrm{E}$ - culture supplemented with the pea proteins extract, $\mathrm{H}$ - culture supplemented with the pea protein hydrolysate. Significantly different values $(p<0.05)$ of proliferating Caco- 2 cells are indicated with different digits

protein extract triggered by the two hours pepsin hydrolysis (as obtained in this study, Fig. 1) is classified as a high degree hydrolysis [16] providing extensive hydrolysates which therefore may potentially be used in the production of above mentioned food.

Peptides and glycopeptides released by the hydrolysis of food proteins may significantly modulate the condition and activity of intestinal ecosystem thus exerting an effect far beyond solely nutritional. There is a growing evidence that stable autochthonic microflora of the gastrointestinal tract determine maintenance as well as strengthening of the intestinal barrier consisting of epithelial cells layer, thus being a guarantor of selective permeability and protecting the human organism from invasion of harmful microorganisms as well as food allergens and other detrimental factors [17]. The bacterial adhesion to the enterocytes not only determines their ability to stay in the mobile environment of the small intestine and their access to nutrients but also beneficially impact human organism by stimulating the immunological system and creating the barrier protecting from the invasion of pathogens [12]. Due to the fact that the research methodology preclude the assessment of bacterial adhesion in vivo, various in vitro models using cell line cultures are being used to examine the bacterial adhesion. Despite the fact that the Caco-2 cell line was originally obtained from a human colon adenocarcinoma, it is most frequently used in various research due to acquisition of many small intestinal cell phenotypes [18].

Although both of studied substrates stimulated the adhesion of bacteria to the Caco-2 cell lines (Fig. 2), solely the pea protein hydrolysates stimulated an increased adhesion of beneficial bacteria from the genera Lactobacillus and Enterococcus (Fig. 2). The obtained results are undoubtedly caused by many mechanisms determining the adhesion. The examined substrates serve as a source of both nutrients 
and energy what was demonstrated in the study of Świątecka et al. [12], stimulating the proliferation of lactobacilli and enterococci thus increasing the number of competitors for the adhesion sites located on the Caco- 2 cells. Bacteria displaying similar metabolic profiles are probable to communicate with each other in order to mutually activate the competition for both nutrients and bond sites on the surface of the eukaryotic cells. That may explain the increase in adhesion of bacteria from genera Lactobacillus and Enterococcus in the heterogeneous culture supplemented with the pea protein hydrolysate (Fig. 2), even though the adhesion of bacterial monocultures was not different when compared to the control [12].

Reaching the small intestine, food protein hydrolysates - not only act as a source of nutrients for the human organism and a modulator of bacterial homeostasis but also influence the local environment, modifying metabolic activities of enterocytes. Good physiological condition of the intestinal epithelium, determined by the proper metabolism and integrity, shape the proper functioning of its absorbing and secreting functions and consist a guarantor of the selective permeability that protects the human organism from invasion of unwanted microbes and deleterious food allergens [17]. Optimal proliferation rate is crucial to maintain the proper permeability of the intestinal barrier to avoid bacterial translocation and antigen passage. Nutrients may directly influence intestinal mucosal turnover, repair and adaptation. Both the pea protein extract and the pea protein hydrolysate strongly hindered the proliferation activity of Caco-2 cells (Fig. 3), thus suggesting the occurrence of fractions of inhibitory activity towards metabolism of eukaryotic cells. The deepened inhibitory activity of the pea protein hydrolysate in comparison to the pea protein extract on the proliferation of enterocytes may be triggered by hydrolysis of proteins that led to liberation of inhibitory amino-sequences. Hindered enterocytes mitosis when exposed to the examined substrates may bring about weakening the intestinal barrier by impeding its renewal. In addition, the examined substrates triggered the significant release of IL-8 from the enterocytes (Fig. 4). Interleukin 8 is an $\alpha$-chemokine that, when secreted by intestinal epithelial cells, participates in the attraction of leukocytes into the intestinal mucosa [19]. Thus, by recruiting and activating immune cells, IL-8 may play an important role in inflammation. The hindrance of enterocytic proliferation combined with IL-8 secretion may be a stimuli for leaking of the intestinal barrier and translocation of pathogenic and opportunistic bacteria as well as food allergens, thus triggering or deepening the inflammation.

It could be speculated, that the alteration of the profile of the bacteria adhering to the Caco-2 cells, with significant predominance of Lactobacillus/Enterococcus, may abolish the detrimental effect of pea protein extract and its hydrolysates exerted on the intestinal epithelium. The gastrointestinal tract of a human is a highly complex ecosystem, homeostasis of which is determined by the cooperation of microbiota and the intestinal epithelium. Thus, despite of the enterocytic proliferation hindrance and proinflammatory cytokine secretion by examined substrates, their positive impact on bacteria may compensate the effect on the epithelial cells in order to maintain the intestinal homeostasis.

This work was supported financielly by the statutory fund of the Institute of Animal Reproduction and Food Research of the Polish Academy of Sciences.

\section{References}

1. Korhonen H, Pihlanto A (2003): Food-derived bioactive peptides - opportunities for designing future foods. Curr Phar Des 9: 1297-1308.

2. Möller NP, Scholz-Ahrens KE, Roos N, et al. (2008): Bioactive peptides and proteins from foods: indication for health effects. Eur J Nutr 47: 171-182.

3. Baraniak B, Świeca M (2008): Proteolytic modification of selected legume flours. Acta Sci Pol Technol Aliment 7: 41-48.

4. Messina MJ (1999): Legumes and soybeans: overview of their nutritional profiles and health effect. Am J Clin Nutr 70: 439450.

5. Świątecka D, Świątecki A, Kostyra H, et al. (2010): The impact of pea protein hydrolysates on bacterial physiological activity - an in vitro study. Int J Food Microbiol 140: 263-270.

6. Simpson RJ (2004): Purifying proteins for proteomics. CSHL PRESS, New York.

7. Weiss W, Vogelmeier C, Görg A (1993): Electrophoretic characterization of wheat grain allergens from different cultivars in bakers' asthma. Electrophoresis 14(8): 805-816.

8. Bradford MM (1976): A rapid and sensitive method for quantification of microgram quantities of protein utilizing the principle of protein-dye-binding. Anal Biochem 72: 248-254.

9. Adler-Nissen J (1976): Enzymatic hydrolysis of proteins for increased solubility. J Agric Food Chem 24: 1090-1093.

10. Laemmli UK (1970): Cleavage of structural proteins during assembly of the head bacteriophage T4. Nature 227: 680-685.

11. Peterson MD, Mooseker MS (1993): An in vitro model for the analysis of intestinal brush border assembly I. Ultrastructural analysis of cell contact-induced brush border assembly in Caco2BBe cells. J Cell Sci 105: 445-460.

12. Świątecka D, Iwan M, Świątecki A, et al. (2010): The impact of glycated pea proteins on bacterial adhesion. Food Res Int 43: $1566-1576$.

13. Gauthier SF, Pouliot Y (2003): Functional and biological properties of peptides obtained by enzymatic hydrolysis of whey proteins. J Dairy Sci 86: 78-87.

14. Clemente A (2000): Enzymatic protein hydrolysates in human nutrition. Trends Food Sci Technol 11: 254-262.

15. Whitehurst RJ, Low BA (2002): Enzymes in food technology. Blackwell Publ. Sheffield.

16. Pedroche J, Yust MM, Girón-Calle J, et al. (2003): Plant protein hydrolysates and tailor-made foods. Electron $\mathrm{J}$ Environ Agric Food Chem 2: 233-235.

17. Snoeck V, Goddeeris B, Cox E (2005): The role of enterocytes in the intestinal barrier function and antigen uptake. Microbes Infect 7: 997-1004.

18. Pinto M, Robine-Leon S, Appay MD, et al. (1983): Enterocyte-like differentiation and polarization of the human colon carcinoma cell line Caco-2 in culture. Biol Cell 47: 323-330.

19. Daig R, Rogler G, Aschenbrenner E, et al. (2000): Human intestinal epithelial cells secrete interleukin-1 receptor antagonist and interleukin- 8 but not interleukin-1 or interleukin-6. Gut 46: 350-358. 